\title{
Preparation of Gallium Nitride Powders and Nanowires from a Gallium(III) Nitrate Salt in Flowing Ammonia
}

\author{
Woo-Sik Jung \\ School of Chemical Engineering and Technologv, College of Engineering. Yeungnam Lniversin, Gyongsan 712-719. Korea \\ Received June 24, 2003
}

\begin{abstract}
Gallium nitride ( $\mathrm{GaN}$ ) powders were prepared by calcining a gallium(III) nitrate salt in flowing ammonia in the temperature ranging from 500 to $1050^{\circ} \mathrm{C}$. The process of conversion of the salt to GaN was monitored by $\mathrm{X}$-ray diffraction and ${ }^{11} \mathrm{Ga}$ MAS (magic-angle spinning) NMR spectroscopy. The salt decomposed to $₹ \mathrm{Ga}_{-} \mathrm{O}_{3}$ and then converted to $\mathrm{GaN}$ without $\gamma \beta \mathrm{Ga}_{2} \mathrm{O}_{3}$ phase transition. It is most likely that the conversion of $* \mathrm{Ga}_{2} \mathrm{O}_{3}$ to $\mathrm{GaN}$ does not proceed through $\mathrm{Ga}_{2} \mathrm{O}$ but stepwise via amorphous gallium oxynitride $\left(\mathrm{GaO}_{\mathrm{N}}\right.$ ) as intermediates. The GaN nanowires and microcrystals were obtained by calcining the pellet containing a mixture of $\gamma-\mathrm{Ga}_{2} \mathrm{O}_{3}$ and carbon in flowing ammonia at $900^{\circ} \mathrm{C}$ for $15 \mathrm{~h}$. The growth of the nanowire might be explained by the vapor-solid (VS) mechanism in a confined reactor. Room-temperature photoluminescence spectra of as-synthesized GaN powders obtained showed the emission peak at $363 \mathrm{~mm}$.
\end{abstract}

Key Words : Gallium nitride. Powder. Nanowire, Confined reactor. ${ }^{\circledR 1}$ Ga MAS NMR

\section{Introduction}

One of Group III-V nitrides. gallium nitride (GaN) with a bandgap of $3.4 \mathrm{eV}$ at room temperature is known to be a candidate material for highly effective blue light emitting diodes and short wavelength laser diodes for high optical storage. 'Sapphire is the most widely used substrate for the thin-film growth of $\mathrm{GaN}$. However. there exists severe mismatch both in lattice parameters and thermal expansion coefficients. Such a large mismatch induces stresses in the first few layers of GaN grown on sapphire. A trend for the future is therefore. the development of $\mathrm{GaN}$ substrates for homoepitaxy by fabricating $\mathrm{GaN}$ bulk single crystals and wafers. Sublimation ${ }^{2}$ and high-pressure solution methods ${ }^{3}$ are considered for crystal growth of GaN. The methods demand the availability of well-characterized GaN powder source with high purity and single phase. Balkas and Davis synthesized bulk GaN powders by reaction of ammonia with gallium metal or $\mathrm{Ga}_{2} \mathrm{O}_{3}$ as a $\mathrm{Ga}$ source. ${ }^{+}$

In this report we synthesize $\mathrm{GaN}$ powders nanowires and microcrystals using a gallium(III) nitrate salt. which is one of readily available Ga sources. The process of conversion of the salt to $\mathrm{GaN}$ was monitored by $\mathrm{XRD}$ and ${ }^{71} \mathrm{Ga}$ magicangle spinning (MAS) NMR spectroscopy. The results are compared with those obtained with other Ga sources.

\section{Experimental Section}

The precursor material $\mathrm{Ga}\left(\mathrm{NO}_{3}\right)_{3} \cdot \mathrm{xH}_{2} \mathrm{O}$ (Aldrich. 99.9\%) was used without further purification. $\mathrm{GaN}$ powders were synthesized by calcining the salt powders in a crucible under a flow of ammonia (Showadenko Co. 99.999\%) in the temperature range $500-1050{ }^{\circ} \mathrm{C}$ for $3 \mathrm{~h}$. The flow rate of

\footnotetext{
Phone: +82-53-810-2528: Fax: +82-53-814-8790: E-mail: wsingàyu.acks
}

anumonia was $50 \mathrm{~mL} \mathrm{~min}{ }^{-1}$. GaN nanowires and microcrystals were obtained by calcining pellets containing a mixture of $\gamma-\mathrm{Ga}_{2} \mathrm{O}_{3}$ and carbon at $900^{\circ} \mathrm{C}$ for $15 \mathrm{~h}$ under a flow of anmonia. The pellets were prepared as follows: a gallium(III) nitrate salt was mixed with carbon (mole ratio of the salt to carbon $=1: 2$ ) in water and evaporated to dryness. The mixture powder was precalcined at $500^{\circ} \mathrm{C}$ for $2 \mathrm{~h}$ under a flow of nitrogen and pressed into pellets. The sample was taken from the furnace after it was cooled to the room temperature under a flow of ammonia.

The conversion of the salt to GaN was monitored by XRD (Rigaku DMX-2500 diffractometer with $\mathrm{Cu}-\mathrm{K} \alpha$ radiation operating at $40 \mathrm{kV}$ and $100 \mathrm{~mA}$ ) and ${ }^{71} \mathrm{Ga}$ magic-angle spinning (MAS) NMR spectroscopy. High-resolution ${ }^{71} \mathrm{Ga}$ MAS NMR spectra were recorded at ambient temperature using a Varian Unity INOVA 600 spectrometer running at $183.0 \mathrm{MHz}$. The rotor used as sample chamber was spun at $14 \mathrm{kHz}$ during data collection. Chemical shifts $(\delta)$ were referenced to $1 \mathrm{M}$ aqueous gallium(III) nitrate solution. The morphology of GaN products was investigated by scanning electron microscopy (SEM. Hitachi S-4100). Room-temperature photoluminescence (PL) measurements of as-syinthesized GaN powders obtained were carried out by using a He$\mathrm{Cd}$ laser (excitation wavelength $=325 \mathrm{~nm}$ ).

\section{Results and Discussion}

The sample powders obtained by calcining gallium(III) nitrate were agglomerated in a form of lump and therefore lightly crushed by hand in an agate mortar and pestle for the analysis. Figure 1 shows XRD patterns of samples synthesized at different temperatures. Weak diffraction peaks of the sample obtained at $600^{\circ} \mathrm{C}$ are assigned to $\mathrm{K}^{\circ} \mathrm{Ga}_{2} \mathrm{O}_{3}{ }^{5}$ with low crystallinity. Decomposition of gallium(III) nitrate powders in air at $600^{\circ} \mathrm{C}$ produced $\beta-\mathrm{Ga}_{2} \mathrm{O}_{3}$. This means that the rate of reaction between $\gamma-\mathrm{Ga}_{2} \mathrm{O}_{2}$ and anmonia is faster than that 


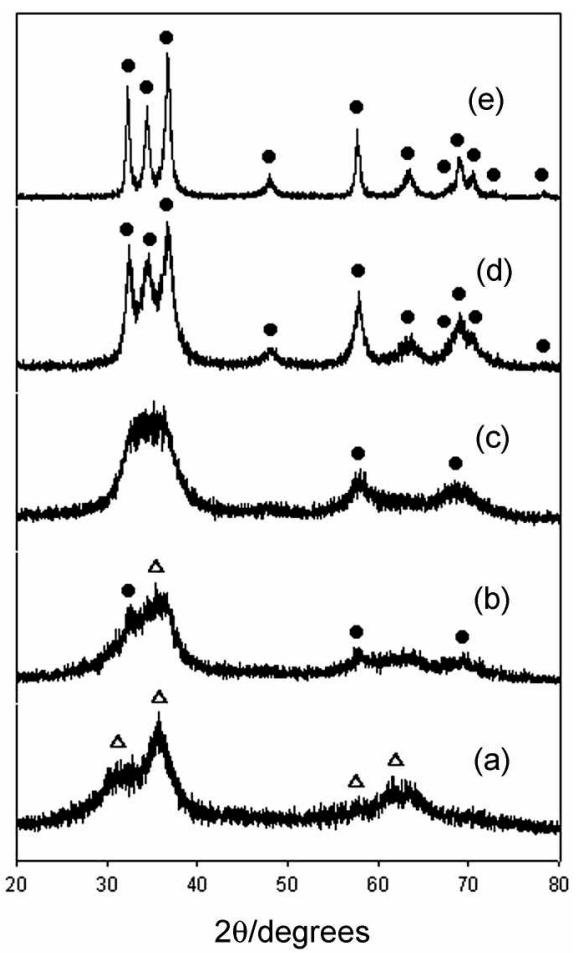

Figure 1. XRD pattents of powders obtained by calcination of $\mathrm{Ga}\left(\mathrm{NO}_{3}\right)_{3}: \mathrm{xH}_{2} \mathrm{O}$ in flowing annmonia at various temperatures for 3 h: (a) $600{ }^{\circ} \mathrm{C}$, (b) $700^{\circ} \mathrm{C}$, ic) $800^{\circ} \mathrm{C}$, (d) $900^{\circ} \mathrm{C}$, (e) $1000^{\circ} \mathrm{C}$ $\mathrm{GaN}: \Delta, \gamma-\mathrm{Ga}_{-} \mathrm{O}_{3}$.

of phase transformation from $\gamma$ to $\beta$ - $\mathrm{Ga}_{2} \mathrm{O}_{3}$. The intensities of the peaks assigned to $\gamma-\mathrm{Ga}_{3} \mathrm{O}_{3}$ decrease and those of the peaks assigned to $\mathrm{GaN}^{4}$ increase with the reaction temperature. The XRD pattern of the sample obtained at $800^{\circ} \mathrm{C}$ has broad peaks of $\mathrm{GaN}$, and is very similar to that of $\mathrm{GaN}$ nanocrystals in a silica xerogel matrix. ${ }^{6}$ The nanocrystals were prepared by calcination of galliun(III) nitrate incorporated into a silica xerogel. followed by nitridation of $900{ }^{\circ} \mathrm{C}$ for $48 \mathrm{~h}$. In the case of the sample obtained at the temperatures above $900^{\circ} \mathrm{C}$. there are no detectable peaks other than the peaks assigned to $\mathrm{GaN}$, as shown in Figure 1 .

Each powder obtained was also characterized by ${ }^{71} \mathrm{Ga}$ MAS NMR spectroscopy. Solid-state NMR spectroscopy might be a more powerful probe than XRD in characterizing poorly crystalline materials because the latter provides little information about central-metal distribution owing to lack of long-range order. The NMR spectroscopy is also a useful tool for identification of defects in crystal structure. ${ }^{7} \mathrm{Up}$ to now most investigators have employed the powder X-ray diffraction (XRD) to deternine whether or not $\mathrm{GaN}$ powder synthesized is of high purity and single phase. ${ }^{4}$ But nitrogen deficiency in the $\mathrm{GaN}$ can be hardly revealed by the powder $\mathrm{XRD}$. though $\mathrm{GaN}$ is expected to be nitrogen deficient in its synthetic process.

Figure 2 shows ${ }^{71} \mathrm{Ga}$ MAS NMR spectra of samples synthesized at different temperatures. The poorly resolved spectrum of $\gamma \mathrm{Ga}_{3} \mathrm{O}_{3}$ obtained at $600{ }^{\circ} \mathrm{C}$ shows two broad peaks at 28 and $185 \mathrm{ppm}$. Each peak is assigned to sixcoordinated $\left(\mathrm{GaO}_{6}\right)$ and four-coordinated $\left(\mathrm{GaO}_{4}\right)$ gallium.

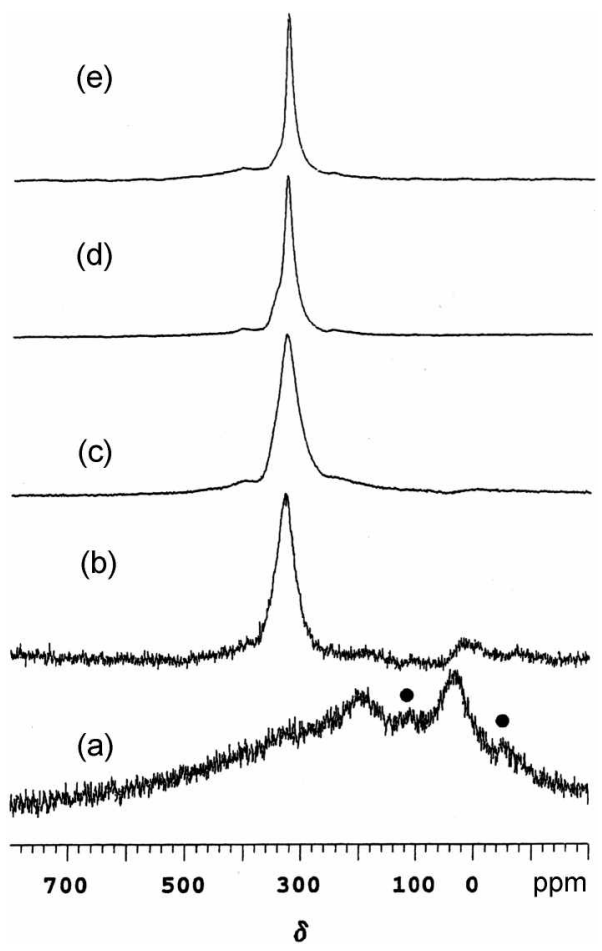

Figure 2. "Gá MAS NMR spectra of powders obtained by calcination of $\mathrm{Ga}\left(\mathrm{NO}_{3}\right)_{3} \cdot \mathrm{xH}_{2} \mathrm{O}$ in flowing ammonia at various temperatures for $3 \mathrm{~h}$ : (a) $600^{\circ} \mathrm{C}$, (b) $700^{\circ} \mathrm{C}$, (c) $800^{\circ} \mathrm{C}$, (d) $900^{\circ} \mathrm{C}$, (e) $1000{ }^{\circ} \mathrm{C}$. 'l'he peaks marked by closed circles are the spinning sidebands.

respectively. The peak patten is similar to that of $\gamma-\mathrm{Al}_{2} \mathrm{O}_{3}^{8}$ because $\kappa_{-\mathrm{Ga}_{2}} \mathrm{O}_{3}$ has a (defective) spinel-type structure similar to that of $\gamma-\mathrm{Al}_{2} \mathrm{O}_{3}$. In the sample obtained at $700{ }^{\circ} \mathrm{C}$ the peak (at $330 \mathrm{ppm}$ ) assigned to $\mathrm{GaN}^{y}$ is observed along with the very weak peaks assigned to $\mathrm{G}_{\mathrm{G}} \mathrm{O}_{3}$. With increasing reaction temperature. the former peak becomes more narrow because of increase in crystallinity. The GaN peak for samples obtained at $900^{\circ} \mathrm{C}$ has a small shoulder on its low-field side. The shoulder may be due to some point defects in crystalline GaN. The peak at 425 ppm. ${ }^{7}$ which is assigned to nitrogen-deficient $\mathrm{GaN}\left(\mathrm{GaN}_{1 . x}\right.$ where $\left.0<\mathrm{x}<1\right)$, was not observed for samples in this study.

The conversion of a gallium(III) nitrate salt to $\mathrm{GaN}$ in flowing ammonia is accompanied by weight loss, as shown in Figure 3. Variation in the weight loss $\%$ with increasing temperature is divided into four segments. The first one is below $600{ }^{\circ} \mathrm{C}$, where the salt decomposes to $\gamma-\mathrm{Ga}_{2} \mathrm{O}_{3}$. The dissociation of ammonia seems to be very difficult below $600{ }^{\circ} \mathrm{C}$. in view of the fact that the weight loss $\%$ of the sample obtained at $500^{\circ} \mathrm{C}$ for $20 \mathrm{~h}$ was almost the same as that of the sample at $600^{\circ} \mathrm{C}$ for $3 \mathrm{~h}$ within experimental errors. The second one is between 600 and $900^{\circ} \mathrm{C}$. where $\gamma$ $\mathrm{Ga}_{2} \mathrm{O}_{3}$ converts to $\mathrm{GaN}$. The third one between 900 and $1000^{\circ} \mathrm{C}$ is almost a plateaul. where $\mathrm{GaN}$ powders become crystalline and denser. The last one is above $1000^{\circ} \mathrm{C}$. where $\mathrm{GaN}$ powders sublime and/or decompose. The discrepancy between experimental and theoretical yields for the product obtained at $1050^{\circ} \mathrm{C}$ for $5 \mathrm{~h}$, which has been reported by 


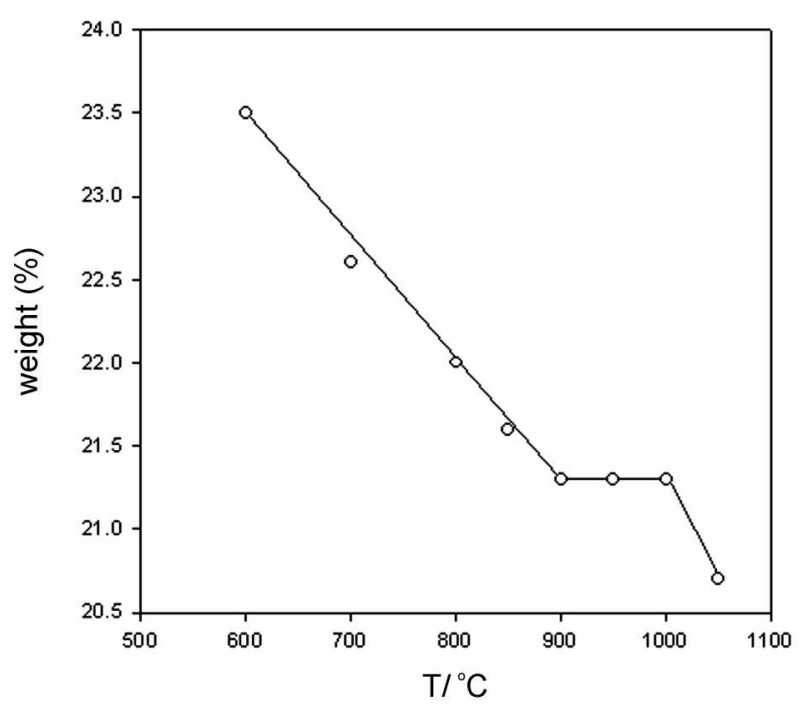

Figure 3. Variation in weight $\%$ of $\mathrm{Ga}\left(\mathrm{NO}_{3}\right)_{2} \cdot \mathrm{xH}_{2} \mathrm{O}$ as a function of calcination temperature for $3 \mathrm{~h}$.

Wood et al., ${ }^{11}$ may be attributed to the sublimation and/or decomposition of $\mathrm{GaN}$. The value of $\mathrm{x}$ in $\mathrm{Ga}\left(\mathrm{NO}_{3}\right)_{3} \cdot \mathrm{xH}_{3} \mathrm{O}$ used in this study was determined to be 7.6 from the weight loss $\%$ of the sample obtained at $950^{\circ} \mathrm{C}$. assuming that the sample is a single phase of $\mathrm{GaN}$.

There was little difference in reactivity of ammonia between $\gamma$ and $\beta-\mathrm{Ga}_{2} \mathrm{O}_{3} .{ }^{11}$ though the latter is thermodynanically more stable than the former. It is supposed in a previous paper ${ }^{31}$ that the conversion of $\beta-\mathrm{Ga}_{2} \mathrm{O}_{3}$ to $\mathrm{GaN}$ does not proceed through gallium(I) suboxide $\left(\mathrm{Ga}_{3} \mathrm{O}\right)$ but stepwise via amorphous gallium oxynitrides $\left(\mathrm{GaO}_{\mathrm{N}} \mathrm{N}_{\mathrm{Y}}\right)$ intermediates. It is speculated that the gallium oxynitride is formed by the dissociation of ammonia adsorbed on the surface of $\mathrm{Ga}_{2} \mathrm{O}_{3}$. As the nitridation proceeds, the oxygen content in the intermediates gradually decreases. leading to the complete conversion to $\mathrm{GaN}$. The mechanism involving $\mathrm{GaO}_{\mathrm{N}} \mathrm{N}_{\mathrm{y}}$ intermediates is supported by the following fundings. First, the sample obtained at $800^{\circ} \mathrm{C}$ turned into a mixture of $\mathrm{GaN}$ and $\beta-\mathrm{Ga}_{2} \mathrm{O}_{3}$ by its calcinations at $700{ }^{\circ} \mathrm{C}$ in air for $\mathrm{l} h$. This derives from the conversion of a small amount of $\mathrm{GaO}_{x} \mathrm{~N}_{y}$ intermediates to $\beta-\mathrm{Ga}_{2} \mathrm{O}_{3}$ because the oxidation of $\mathrm{GaN}$ to $\mathrm{Ga}_{2} \mathrm{O}_{3}$ is very slow below $900^{\circ} \mathrm{C}$. Second, the morphology of $\gamma \cdot \mathrm{Ga}_{2} \mathrm{O}_{3}$ is retained on its conversion to $\mathrm{GaN}$. If the mechanism involving a $\mathrm{Ga}_{2} \mathrm{O}$ intermediate is valid, the retention is expected to be impossible for the mechanism.

In order to prevent the product powder from being agglomerate, a mixture of $\mathrm{Ga}\left(\mathrm{NO}_{3}\right)_{3} \cdot \mathrm{xH}_{2} \mathrm{O}$ and charcoal (mole ratio $=1: 20$ ) in aqueous solution was evaporated to dryness and then calcined in flowing anmonia at $950^{\circ} \mathrm{C}$ for $1 \mathrm{~h}$, followed by burning up the charcoal at $700^{\circ} \mathrm{C}$ in air. The powder was much unagglomerated than powders obtained without using charcoal. As shown in Figure 4(a). the morphology is very similar to that of powders synthesized by the aerosol-assisted vapor phase synthesis method using aqueous galliun(III) salt solution, ${ }^{\text {i) }}$ particularly in that agglomerates are composed of faceted particles.
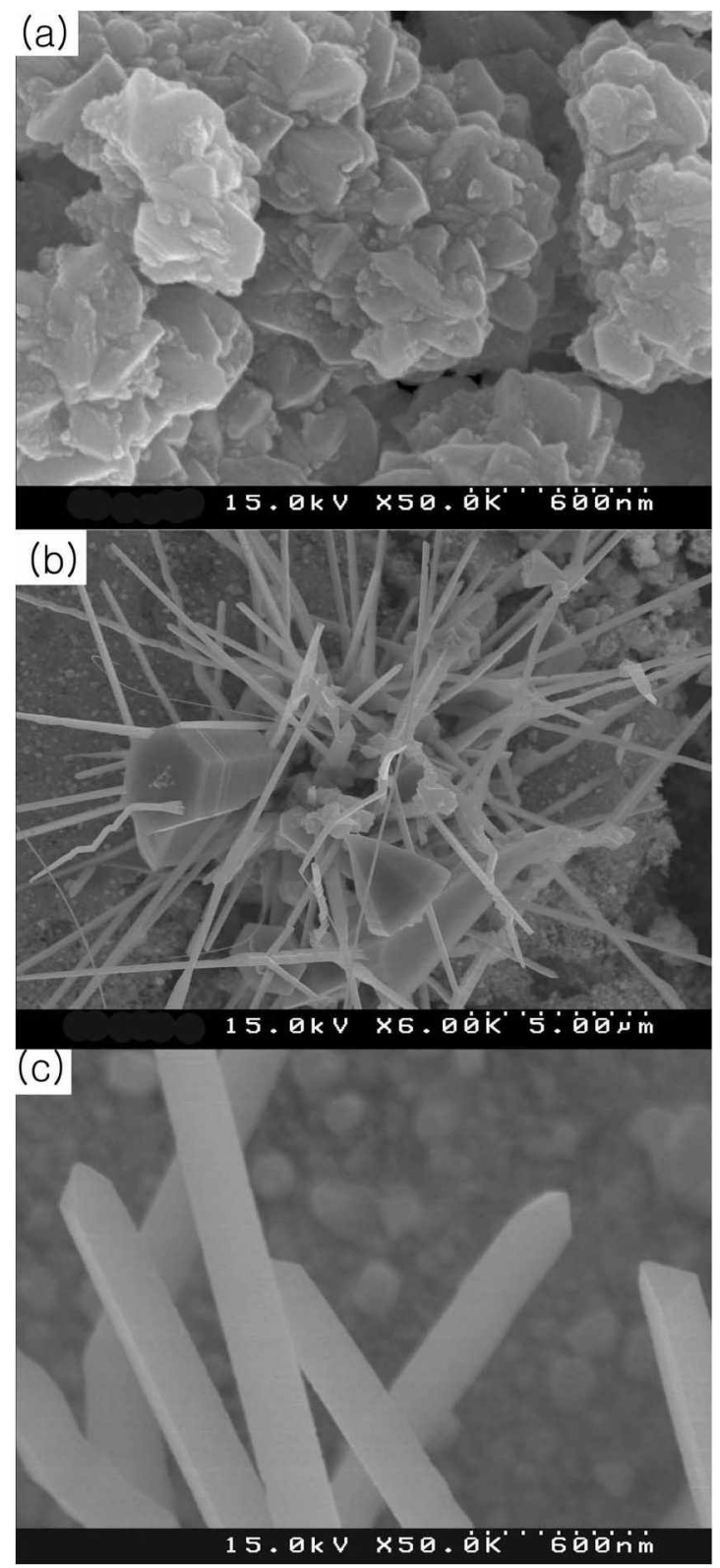

Figure 4. SEM micrographs of (a) the GaN powders (a) obtained by calcining a mixture of $\mathrm{Ga}\left(\mathrm{NO}_{3}\right)_{3} \cdot \mathrm{xH}_{2} \mathrm{O}$ and carbon (mole ratio = $l: 20$ ) at $950{ }^{\circ} \mathrm{C}$ for $l \mathrm{~h}$ and of $(b, c) \mathrm{GaN}$ nanowires and microcrystals obtained by calcining the pellet containing a misture of $* \mathrm{Ga}_{2} \mathrm{O}_{3}$ and carbon at $900^{\circ} \mathrm{C}$ for $15 \mathrm{~h}$ in flowing ammonia.

When a mixture of $\gamma \mathrm{Ga}_{2} \mathrm{O}_{3}$ and carbon was pressed into a pellet and then calcined at $900^{\circ} \mathrm{C}$ for $15 \mathrm{~h}$ under a flow of ammonia. the confinement effect was observed on morphology of GaN. As shown in Figures 4(b) and 4(c). a lot of GaN nanowires and some hexagonal microcrystals soared up out of surface of the pellet. Most of the nanowires are as thick as $200 \mathrm{~nm}$ and some nanowires are about $50 \mathrm{~nm}$ in diameter. No droplets were observed at tips (Figure 4(c)). indicating that the nanowires do not grow by the vapor-liquid-solid (VLS) mechanism. Peng et al. ${ }^{13}$ proposed the reaction mechanism on growth of $\mathrm{GaN}$ nanowires during conversion of a mixture of $\mathrm{Ga}_{2} \mathrm{O}_{3}$ and carbon to $\mathrm{GaN}$. According to the mechanism, $\mathrm{Ga}_{2} \mathrm{O}_{3}$ should be reduced to gaseous $\mathrm{Ga}_{2} \mathrm{O}$ by 


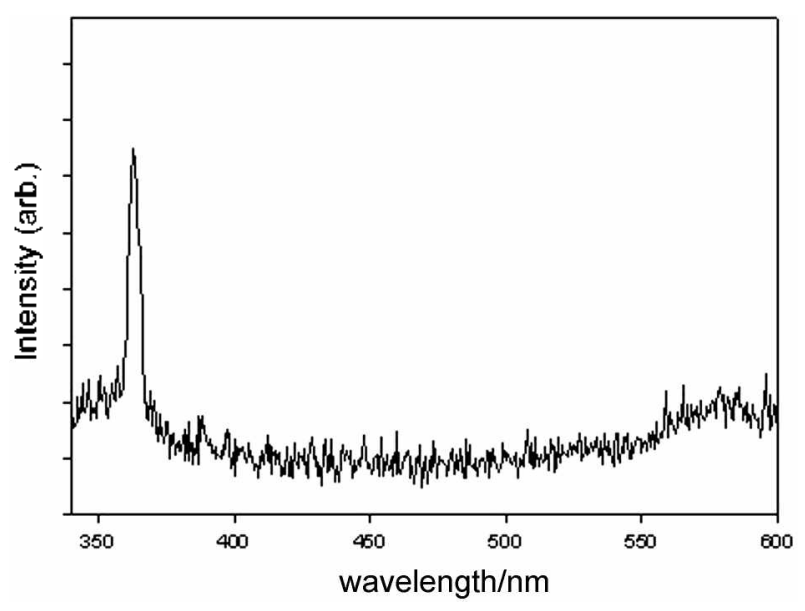

Figure 5. Room-temperature PL spectrum of the powders obtamed by calcination of $\mathrm{Ga}\left(\mathrm{NO}_{3}\right)_{2} \times \mathrm{xH}_{2} \mathrm{O}$ at $900{ }^{\circ} \mathrm{C}$ for 3 h in tlowing anmonona.

carbon and then the reaction of $\mathrm{Ga}_{3} \mathrm{O}$ with anmonia result in formation of $\mathrm{GaN}$. If such a gaseous intermediate is involved during reaction. some weight loss of the intermediate must take place in flowing anumonia. But the anount of $\beta-\mathrm{Ga}_{2} \mathrm{O}_{3}$ was quantitatively obtained by calcination of a $\left(\mathrm{NH}_{4}\right)\left[\mathrm{Ga}(\right.$ edta) $] \cdot 2 \mathrm{H}_{2} \mathrm{O}$ complex ${ }^{1+4}$ at $1100^{\circ} \mathrm{C}$ for $3 \mathrm{~h}$ under a flow of nitrogen. followed by burning out the carbon at 700 ${ }^{\circ} \mathrm{C}$ in air. The formation of gaseous $\mathrm{Ga}_{3} \mathrm{O}$ should be, if $\mathrm{Ga}_{3} \mathrm{O}_{3}$ is reduced to gaseous $\mathrm{Ga}_{2} \mathrm{O}$ by carbon. much more feasible because the pyrolysis of the complex gives an intimate mixture of $\mathrm{Ga}_{3} \mathrm{O}_{3}$ and carbon at the molecular level. We propose that $\mathrm{GaN}$ nanowires and microcrystals night grow by the vapor-solid (VS) mechanism. i.e., by sublimationcondensation of $\mathrm{GaN}$ formed through the intermediates $\mathrm{GaO}_{\mathrm{x}} \mathrm{N}_{\mathrm{y}}$ : The growth process of $\mathrm{GaN}$ nanowires in this study is thought to be similar to that in a reaction using nanometer confined reactors such carbon nanotubes ${ }^{15}$ and anodic alunina membranes ${ }^{16}$ Calcination of a mixture of $\gamma-\mathrm{Ga}_{3} \mathrm{O}_{3}$ and carbon, if it was not pressed into pellets, gave neither GaN nanowires nor microcrystals. Thus, the confinement of $\mathrm{GaN}$ in voids among pressurized carbon particles might be responsible for the growth of nanowires and microcrystals of GaN because the confinement is expected to be very favorable for supersaturation of $\mathrm{GaN}$ vapor. It is well known that the degree of supersaturation determines the prevailing growth morphology. A low supersaturation is required for whisker (or nanowire) growth whereas a medium supersaturation support bulk crystal grovth. ${ }^{17}$ Further work is in progress for obtaining homogeneous $\mathrm{GaN}$ nanowires.

The PL spectrum of $\mathrm{GaN}$ powder obtained at $900^{\circ} \mathrm{C}$ is shown in Figure 5. The strong emission peak at $363 \mathrm{~mm}$ is the band edge of $\mathrm{GaN}$ with the wurtzite structure, and the weak and broad peak around $580 \mathrm{~nm}$ corresponds to the well-known yellow band observed in $\mathrm{GaN}^{18}{ }^{18}$ The latter band became more intense for the powders obtained at higher temperatures.

Acknowledgement. This work was supported by grant No. R05-2001-00841 from the Basic Research Program of the Korea Science \& Engineering Foundation. The XRD pattems and ${ }^{71} \mathrm{Ga}$ MAS NMR spectra were recorded at the Yeungnam University Instrumental Analysis Center and Korea Basic Science Institute Daegu Branch, respectively:

\section{References}

1. Ambacher O. J. Pho Di Appl Phws 1998. 31. 2653.

2. Sakai. S.: Kurai, S.; A be, T; Naoi, Y. Jpn. J. Appl. Phws 1996, 35. L77.

3. Porowski. S. J. Crystal Growth 1996. 166. 583.

4. Balkas. C. M.: Davis. R. F. J. Am. Cerom. Soc. 1996. 79. 2309.

5. Joint Committee on Powder Diffraction Standards (ICPDS) Card No. $20(1)-426$

6. Yang. Y: Tran, C.; Leppert, V: Risbud. S. H. Mater: Lett $\mathbf{2 0 0 0 .}$ 43. 240.

7. Jung. W.S.; Park. C.: Han. S. Bull Korean Chem Soc. 2003, 24. 1011 .

8. Stnith. M. E. Appl. Alagn. Reson. 1993. t. 1.

9. Han1. O. H.: Timken. H. K. C.: Oldfield. L. J. Chem. Phys 1988. 89.6046

10. Wood, G. L.: Pruss, E. A.: Paine, R. T. Chom Mater 2001. 13, 12

11. Jung. W-S. Mater: Lett 2002. 57, 110.

12. Wolter. S. D.: Luther. B. P.: Waltemyer. D. L.: Otneby. C.: Mohney. S. E.: Molnar. R. I. Appl. Ph.s. Lett. 1997. 70.2156.

13. Peng. H. Y.: Zhou. X. T.: Wang. N.: Zheng. Y. F.: Liao. L. S.: Shi. W. S.; Lee, C. S.; Lee. S. T. Chem. Phns Lett 2000, 327, 263.

14. Jung. W.-S.: Chung. Y. K.; Shin. D. M.: Kim. S.-D. Bull. Chem. Soc. dpu. 2002, 75, 1263 .

15. Han. W.: Fan. S.: Li.Q: Hu. Y. Science 1997. 277. 1287.

16. Cheng. G. S.: Zhang. L. D.: Zhu. Y.: Fei. G. T.: Li. L.: Mo. C. M.: Mao. Y. Q. Appl. Phys. Lett. 1999. 75. 2455.

17. Camphell. W. B. In In hisker Techologv: Levitt, A. P., Ed. WilevInterscience: New York. U. S. A.. 1970 Chap. 2.

18. Ogino. T., Aoki. M. Jph. f. Appl. Phus. 1980, 19, 2395. 